\title{
Investigation of Flame Characteristics of Ethanol-Gasoline Blends Combustion Using Constant Volume Chamber
}

\author{
Nuriati Baddu, ${ }^{1, *}$, Amir Khalid ${ }^{1}$, Dahrum Samsudin ${ }^{1}$, Izzuddin Zaman ${ }^{2}$, and Bukhari \\ Manshoor $^{2}$ \\ ${ }^{1}$ Combustion Research Group (CRG), Centre for Energy and Industrial Environment Studies (CEIES), \\ Faculty of Mechanical and Manufacturing Engineering, Universiti Tun Hussein Onn Malaysia, 86400 \\ Batu Pahat, Johor, Malaysia
}

\begin{abstract}
The stricter on emission legislation and growing demands for lower fuel consumption require significant efforts to improve combustion efficiency while satisfying the demand of emission quality. Gasoline blend with ethanol provided advantages due to its self-sustaining concept and high octane number which can be influenced to the combustion process. The purpose of this study is to investigate the effect on the emission and flame propagation of gasoline under the different blending ratio of ethanol fuel in a constant volume chamber. In this paper, the flame propagation of ethanol blends with gasoline in a constant volume chamber has been carried out. The real image is observed by schlieren optical visualization technique and image processing technique. The parameters in this study also included different types of injection pressure, characteristics of flame propagation and different blending ratio of ethanol in gasoline fuels. As a result, the burn rate increases when the content of ethanol percentage in gasoline increased. Therefore, the higher flame propagation area for 0.2 $\mathrm{MPa}, 0.3 \mathrm{MPa}, 0.4 \mathrm{MPa}$ were headed by E15 followed by E10, E5 and gasoline fuels respectively. It is subjected that the increasing of ethanol percentage blends with gasoline could lead to the reduction of $\mathrm{CO}, \mathrm{HC}$ and NOX emissions. However, the $\mathrm{CO} 2$ emission is higher due to the combustion process was enhanced.
\end{abstract}

\section{Introduction}

The significant growth of the population and changes in lifestyles had caused the consumption of energy increased. Major portion of energy supplies are presently based on fossil-fuels petroleum [1-3]. However, the energy sources are limited on the earth, thus the replacement of gasoline by liquid fuel produced from renewable sources is high priority in many countries at twentieth century [4-5]. Ethanol is widely promoted as a clean-burning, renewable fuel that could help wean the nation from oil, would likely cause more ozonerelated health problems than gasoline [6]. Bioethanol has attracted attention worldwide due

* Corresponding author: yatiepytie@gmail.com 
to its potential to use as an alternative automotive fuel [7]. Alcohol fuels have been used in internal combustion engines for many decades. In 1826, Samuel Morey developed an engine that can be used by ethanol fuels [8]. The use of ethanol blends with diesel was a subject of research in the 1980s. At this time, it showed that the ethanol blends were technically acceptable as a fuel for existing engines [9]. Indeed, ethanol showed powerful in some of the first internal combustion engines designed by Otto in the middle of the 19th century [10]. Besides, ethanol can be produced from ligno-cellulosic material like wood, agricultural, forest residues and municipal waste which has potential to be valuable substitute for gasoline fuel. Moreover, ethanol has positive influence on engine performance as well as exhaust emissions since its characteristic and properties are possessed easily [1]. Recently, ethanol has been used extensively as a fuel additive or an alternative fuel in spark ignition (SI) engines due to high octane number that can affect higher compression ratio or advance on sparks timing and clean-burning fuel [10]. The vapor pressure can be increased by using ethanol in gasoline which also can make the mixture up to the volatility standard. Combustion characteristics are playing a significant role to ensure the fuels will combust completely inside the combustion chamber. Meanwhile, it is also important to know the impact of exhaust emission to the air pollution such as carbon monoxide ( $\mathrm{CO})$, hydrocarbon (HC), carbon dioxide $(\mathrm{CO} 2)$, oxides of nitrogen (NOx) by using ethanol blend with gasoline. In this research, the characteristics of combustion process are investigated which focusing on the effects of flame propagation areas and exhaust emission with various concentrations of ethanol content blends with the gasoline fuel (E0, E5, E10 and E15) and different injection pressures $(0.2 \mathrm{MPa}, 0.3 \mathrm{MPa}$, $0.4 \mathrm{MPa}$ ). This experiment was performed by schlieren optical visualization technique based on sampling time $7.6 \mathrm{~ms}, 15.2 \mathrm{~ms}, 32.8 \mathrm{~ms}, 40.4 \mathrm{~ms}, 48.0 \mathrm{~ms}$ and $55.6 \mathrm{~ms}$.

\section{Experimental setup}

The effects of flame propagation and exhaust emission were investigated with different concentrations of ethanol 5vol\% (E5), 10vol\% (E10), 15vol\% E(15) and pure gasoline at the injection pressure $0.2 \mathrm{MPa}, 0.3 \mathrm{MPa}$, and $0.4 \mathrm{MPa}$. All parameters were experimenting with the same base conditions, ambient temperature $345 \mathrm{~K}$, fuel quantity $0.15 \mathrm{ml}$ and equivalence ratio $\phi=1.1$. However, flame propagation and combustion characteristics are essential investigation to the application of ethanol-gasoline blends in spark ignition (SI) engines. The physical and chemical properties indicate the quality of fuel to combust in an SI engine. The engine combustion quality, performance and emission characteristics are fully dependent on these properties. Nevertheless, the properties of ethanol blends with gasoline are shown in the Table 1.

Table 1. Properties of ethanol and petrol [10]

\begin{tabular}{|l|c|c|c|c|}
\hline \multicolumn{1}{|c|}{ Property } & E0 & E5 & E10 & E15 \\
\hline Density $\left(\mathrm{kg} / \mathrm{m}^{3}\right)$ & 757.5 & 759.1 & 760.8 & 776 \\
\hline Reid Vapor Pressure & 53.7 & 59.3 & 59.6 & 58.8 \\
\hline Research octane number & 95.4 & 96.7 & 98.1 & 98.5 \\
\hline Sulfur $(\mathrm{wt} \%)$ & 0.0061 & 0.0059 & 0.0055 & 0.0063 \\
\hline Distillation temperature $\left({ }^{\circ} \mathrm{C}\right)$ & & & & \\
a) Initial boiling point & $35.5-38.8$ & 36.5 & 37.8 & 37.9 \\
b) 10 vol \% & $54.5-56.1$ & 49.7 & 52.9 & 51.7 \\
c) 50 vol\% & $94.4-109.6$ & 88 & $71.1-95.8$ & 72.6 \\
d) 90 vol\% & $167.3-206.3$ & 167.7 & $157-166.4$ & 165.3 \\
e) End point & 197.0 & 202.5 & $197.5-208.4$ & 198.1 \\
\hline Heating Value $(\mathrm{MJ} / \mathrm{kg})$ & $42.58-42.7$ & $40.55-41.78$ & $39.79-41$ & 41.61 \\
\hline
\end{tabular}


Table 2. Experimental specification

\begin{tabular}{|l|l|}
\hline \multicolumn{2}{|c|}{ Experimental Specification } \\
\hline Temperature & $345 \mathrm{~K}$ \\
\hline Type of fuel & Gasoline, E5, E10, E15 \\
\hline Injection Pressure & $0.2 \mathrm{MPa}, 0.3 \mathrm{MPa}, 0.4 \mathrm{MPa}$ \\
\hline Injection system & Electronic Control \\
\hline
\end{tabular}

Table 3. Combustion Chamber specification

\begin{tabular}{|l|l|}
\hline \multicolumn{2}{|c|}{ Combustion Chamber } \\
\hline Material & Mild steel \\
\hline Volume & $400 \mathrm{cc}$ \\
\hline Dimension & $160 \mathrm{~mm} \times 160 \mathrm{~mm} \times 160 \mathrm{~mm}$ \\
\hline Bore & $75 \mathrm{~mm}$ \\
\hline
\end{tabular}

Flame development and combustion characteristics are important to the application of ethanol-gasoline blends in DISI engines due to their unique physical properties. Several physical properties of ethanol-gasoline blends are enabled to have distinguishable combustion behavior due to their flame propagation characteristics. Therefore, the schlieren optical visualization technique is corresponded to make an analysis on flame propagation area and also act as an effective way to understand the combustion of ethanol-gasoline blends on direct injection spark ignition. Table 2 shows the experimental conditions throughout all the experiments.

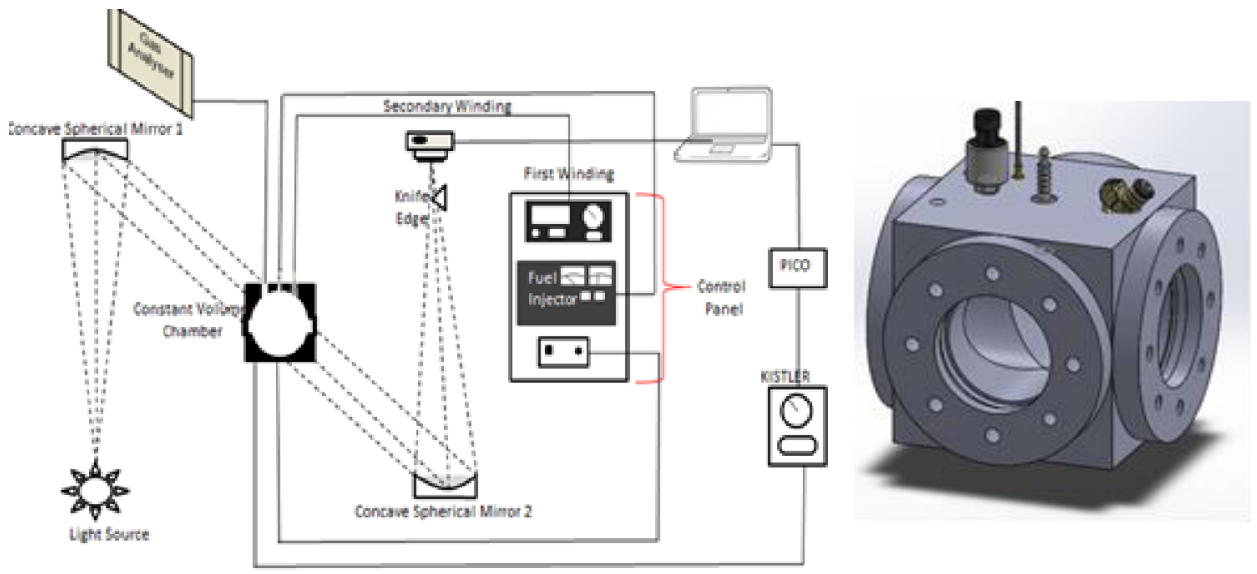

Fig. 1. Schematic Diagram of Schlieren optical visualization technique

Figure 1 shows the schematic of the experiment schlieren setup. The schlieren apparatus consists of two concave mirrors with a focal length 1.524 meter each. A light-emitting diode (LED) light source was projected to a concave mirror with a focal length of 1.524 
meters. The light was deflected by the mirror to an acrylic placed in front of the chamber. Here, a straight and equal intensity of light is maintained by the light-emitting diode (LED) light source. The light was then passed through the test subject and reached the 2nd concave mirror. Then, the parallel light of (light-emitting diode) LED light will deflected again by 2 nd concave mirror. A knife edge with a diameter of $2.5 \mathrm{~mm}$ was used as a schlieren stop which was set at the focal point of the light-emitting diode (LED) light deflected by 2 nd concave mirror. After the knife edge cut the LED light, it was reached to camera lens and the image was taken. Figure 2 and Table 3 shows the schematic diagram of constant volume combustion chamber and its specification. In addition, exhaust emission was measured by a SPTC LTD, Automobile Exhaust Gas Analyzer.

\section{Result and discussions}

Experiments were performed with different blending ratio of ethanol-gasoline fuels and different injection pressures in a constant volume combustion chamber at $345 \mathrm{~K}$ temperature with $0.8 \mathrm{MPa}$ initial filling chamber pressure. First of all, the effect of $0.4 \mathrm{MPa}$ injection pressure on the flame propagation area was investigated. Table 4 shows the flame propagation of injection pressure $0.4 \mathrm{MPa}$, it is clearly seen that the fastest combustion rate are led by the highest additive ethanol in this experiment E15 follow by E10, E5 and gasoline fuels.

Table 4. Flame propagation for bioethanol E15

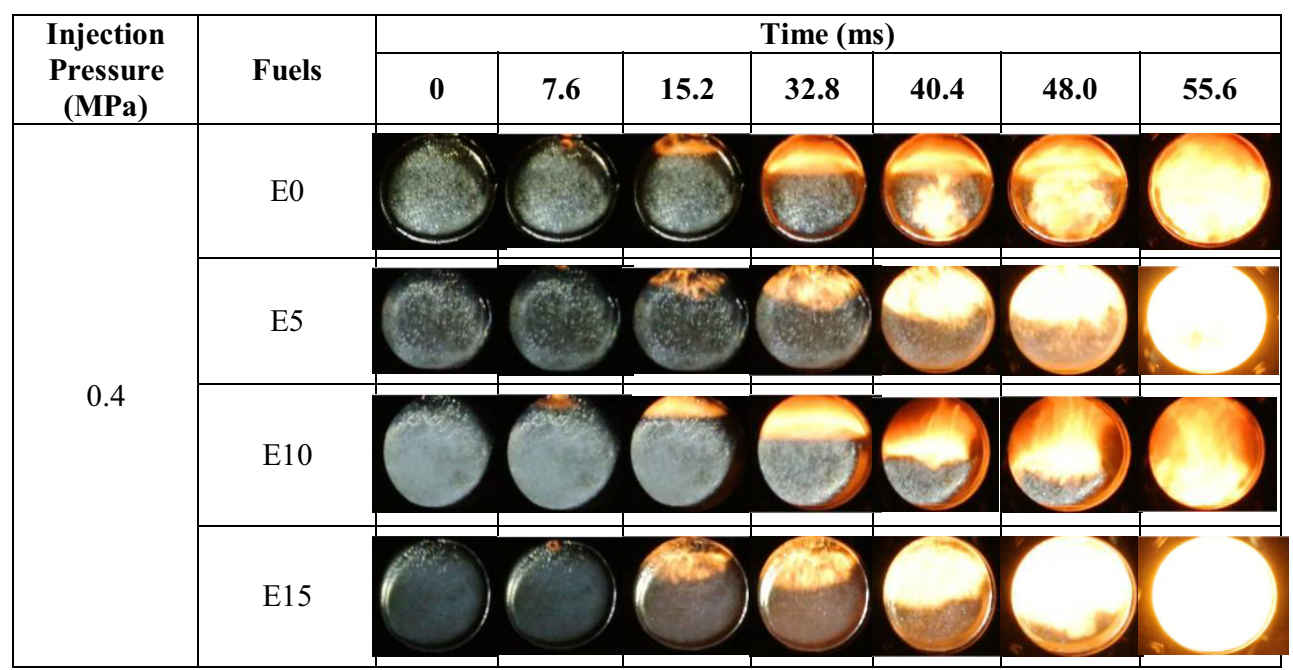




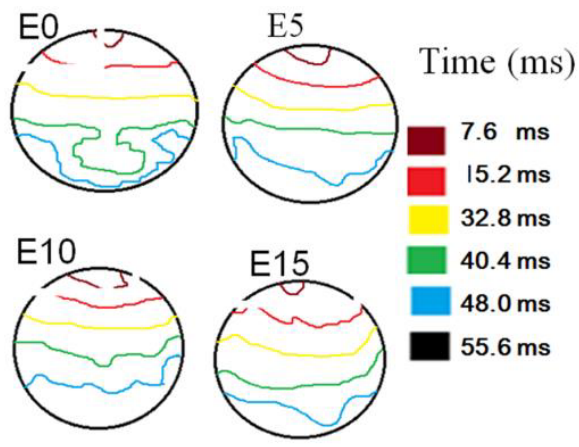

Fig. 3. Flame propagation pattern for injection pressure $0.4 \mathrm{MPa}$

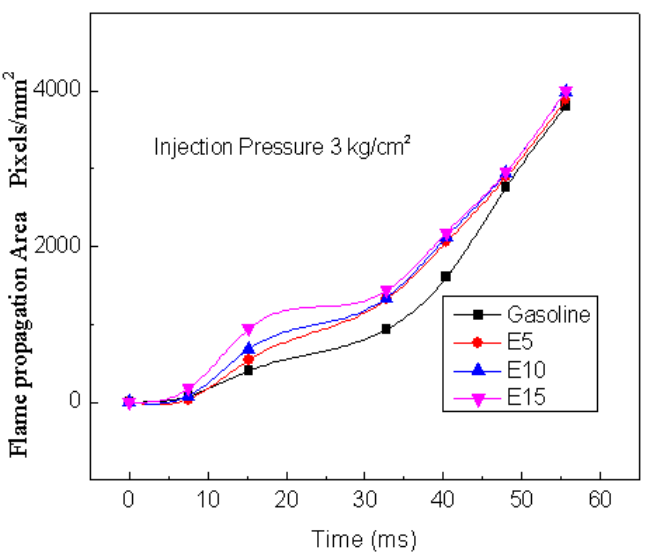

Fig. 4. Graph of flame propagation area against time for injection pressure $0.4 \mathrm{MPa}$

Moreover, Figure 3 and Figure 4 shows the analysis data referred from Table 4, it is clearly illustrated that the flame propagation area under E15 was higher compared to the pure gasoline, E5 and E10 achieved 173.037 pixels $/ \mathrm{mm} 2$ and 941.455 pixels $/ \mathrm{mm} 2$ respectively from time $7.6 \mathrm{~ms}$ to $15.2 \mathrm{~ms}$. It was suggested that the spark discharge ionizes the surrounding ignitable mixture, thus an initial flame kernel form. The downstream evaporating fuel generated a favorable locally air-fuel mixture that sustained a subsequent flame propagation. With the fuel being ignited continuously, the flame quickly expanded to the mixture edges and a shock wave is produced like appearance in ambient, especially at the downstream flame tip. 




Fig. 5. Effects of ethanol blend on emissions

Figure 5 illustrates the pollutant emissions of combustion with ethanol-gasoline blends fuel. The experimental investigation showed that using ethanol-gasoline blends fuel could decrease NOx emission due to the higher heat vaporization of ethanol compared to gasoline which caused the combustion temperature decreased. Besides, the particle diameter of the accumulation mode became smaller when the concentration of ethanol content increased. Apart from that, the aerosol number concentration was found a decreased with increasing the ethanol concentration while it is predicted to lead to complete combustion. For this reason, $\mathrm{CO}$ and NOx emission decreased with increases in ethanol concentration. HC emission was reduced as the oxygen content of ethanol caused the reaction and move towards the complete combustion. Meanwhile, the $\mathrm{CO} 2$ emission increased because of the combustion process is improved.

\section{Conclusion}

This study was done by schlieren optical visualization technique to investigate the flame propagations and exhaust emissions for each types of the ethanol 5vol\% (E5), 10vol\% (E10), $15 \mathrm{vol} \% \mathrm{E}(15)$ and pure gasoline under variant fuel injection pressures of $0.2 \mathrm{MPa}$, $0.3 \mathrm{MPa}$, and $0.4 \mathrm{MPa}$. The following conclusions were obtained:

- Ethanol-gasoline blends influenced the combustion and flame propagation compared to the pure gasoline. The combustion or burn rate increased with increasing the content of ethanol percentage in gasoline. As a result, the highest flame propagation area for 0.4 $\mathrm{MPa}$ was led by E15 followed by E10, E5 and gasoline fuels respectively.

- Reduction of $\mathrm{CO}, \mathrm{HC}$ and NOx emission were achieved, but $\mathrm{CO} 2$ emission increased when the ethanol percentage blends with gasoline increased.

The authors also would like to thank the Ministry of Higher Education Malaysia for supporting this research under Exploratory Research Grant Scheme (ERGS) vot. E032. 


\section{References}

1. B.M. Masum, H.H. Masjuki, M.A. Kalam, I.M.R. Fattah, S.M. Palash, M.J. Abedin, Renew. Sust. Energ. Rev., 24, 209 (2013)

2. A. Khalid, N. Jaat, A. Sapit, A. Razali, B. Manshoor, I. Zaman, A. A. Abdullah, International Journal of Automotive and Mechanical Engineering, 11, 2447 (2015)

3. A. Khalid, K. Hayashi, Y. Kidoguchi, T. Yatsufusa, Effect of air entrainment and oxygen concentration on endothermic and heat recovery process of diesel ignition, (SAE International 2011)

4. F.T. Ansari, A.P. Verma, Experimental determination of suitable ethanol-gasoline blend for spark ignition engine, International Journal of Engineering Research \& Technology, 1, 1 (2012)

5. A. Khalid, N. Tamaldin, M. Jaat, M.F.M. Ali, B. Manshoor, I. Zaman, Procedia Eng., 68, 225 (2013)

6. A. Khalid, Effect of Ambient Temperature and Oxygen Concentration on Ignition and Combustion Process of Diesel Spray, Asian Journal of Scientific Research, 6, 434 (2013)

7. A. Ganguly, P.K. Chatterjee, A. Dey, Renew. Sustainable Energy Rev., 16, 966 (2012)

8. H.O. Hardenberg, Samuel Morey, Atmospheric Engine (SAE International, Warrendale, 1992)

9. B. Kovarik, Automotive History Review, 32, 7 (1988)

10. A. Keskin, Energy Sources. Part A: Recovery, Utilization and Environmental Effects, 32, 1851 (2010) 